\title{
Freud en los medios: una propuesta de exploración de la concepción cinematográfica del Psicoanálisis
}

\section{Freud in the media: A proposal for exploration of cinematic conception of Psychoanalysis}

\author{
Carlos Ramírez Muñoz \\ Universidad de Santiago \\ (Rec: abril 2014 - Acep: junio 2014)
}

\begin{abstract}
Resumen
Revisando los encuentros y las divergencias entre el Cine y el Psicoanálisis, para luego desarrollar algunas nociones del análisis audiovisual de los textos cinematográficos, se realiza un breve recorrido del itinerario de los Psicoanalistas y sus prácticas a lo largo de la historia de la industria cinematográfica. Finalmente se plantea una propuesta metodológica y de investigación, destinada a relevar una cierta teoría en los medios de masa de lo qué sería el Psicoanálisis, por medio del estudio de la reconstrucción cinematográfica de éste.
\end{abstract}

Palabras clave: cine, representación del psicoanalista, análisis del texto audiovisual.

\begin{abstract}
Reviewing the meetings and divergences between the Cinema and Psychoanalysis, then develop some notions of audiovisual analysis of film texts, a brief itinerary of Psychoanalysts and practices performed throughout the history of the film industry. Finally, a methodological and research proposal, designed to relieve some theory on mass media arises what would Psychoanalysis, through the study of film reconstruction of this
\end{abstract}

Keywords: cinema, psychoanalyst representation, visual text analysis.

\footnotetext{
1 Correspondencia dirigida a: Carlos Ramírez Muñoz. Universidad de Santiago, Facultad de Humanidades, Escuela de Psicología, Av. Ecuador 3650- Santiago, Chile. Correo electrónico: carlosantonio.ramirez@gmail.com.
} 


\section{Introducción/Problematización}

\author{
Cine y Psicoanálisis, una historia de des/ \\ encuentros.
}

El 22 de marzo de 1895, en los salones de la Société d'Encouregement a L'industrie Nationale de Paris (Francia), los hermanos Lumiere dan su conferencia sobre el nuevo invento del Cine y ofrecen la primera exhibición de una película: "La salida de los obreros de la fabrica". Ese mismo año Wilhelm Conrad Roentgen, descubre cierto tipo de radiación capaz de ver a través de los materiales denominando este fenómeno rayo $\mathrm{X}$, y Sigmund Freud publica junto a Joseph Breuer, Estudios Sobre la Histeria (1895).

En 1895 la imagen cobra movimiento, la técnica de Roentgen atraviesa las apariencias y Freud inaugura la exploración del inconsciente. En consecuencia, el hombre y la mujer de la modernidad ingresan al siglo XX capturados por los artilugios de la imagen, desprovistos de las certezas del pensamiento clásico y agobiados por su orfandad ante la muerte y Dios. Ante este escenario, los logros de la modernidad -y dentro de estos el Cine y el Psicoanálisis-pueden reconocerse como la empresa del redescubrimiento del mundo, marcada por el deseo de lograr el dominio racional de su entorno.

En este contexto, el Psicoanálisis y el Cine, como productos de la modernidad, nacen al alero del capitalismo industrial (Roudinesco, 2000), participando en la construcción de los horizontes de sentido que definirán la imagen del mundo y del hombre moderno. Esta convergencia, debe pensarse con mayor detención, pues los objetos de análisis a tratar son ambos en cuanto formas de producción y reelaboración de la cultura, pero de manera más precisa, es la relación e imbricación del Cine y el Psicoanálisis, considerando el conjunto de los textos cinematográficos como un fenómeno que excede la condición de obra artística o texto narrativo, y posee el valor de ser un actor provocador y propiciador al interior de las transformaciones de la cultura.

En este sentido, tanto el Psicoanálisis como el Cine participarían en el esbozo de una nueva forma de ver al mundo, como proyección de ideales movilizarán los idearios de su época, dado cuenta de cierto recorrido hacia la modernidad. Desde este prisma, la creación cinemática se presenta como una vía privilegiada para acceder a aquello del Psicoanálisis que se encuentra más allá de la teoría, la historia oficial o los relatos institucionales que otorgarían forma a la práctica psicoanalítica (Gabbard y Gabbard, 1999).
La masividad y plasticidad del Cine permitiría la difusión y apropiación de los distintos contenidos y relatos de la modernidad, de los cuales el Psicoanálisis vendría a ser uno de los privilegiados. Si bien no es el único, pues es posible afirmar que la experiencia Cinematográfica ha sido soporte visual de parte importante de las transformaciones de la sociedad contemporánea, la relación entre el Psicoanálisis y la gran pantalla ha resultado particularmente fecunda en la difusión del pensamiento psicoanalítico (Gabbard y Gabbard, 1999).

En esta lógica, el Psicoanálisis como fenómeno cultural, antes que registro de las transformaciones sociales de fines del siglo XIX, debe considerarse inscritos al interior de dichos cambios. Bajo esta mirada, el itinerario psicoanalítico, en sus diversos campos de desarrollo, constituye un referente singular de las transformaciones culturales pues, junto a la fuerza con que ingresará al escenario de los grandes relatos, es sujeto, a su vez, de las condiciones culturales que permiten su emergencia, expansión y permanencia al interior de las distintas sociedades que lo acogerán.

De esta forma, el Cine se ofrece como una "vía regia" a las representaciones icónicas y diversas de las transformaciones culturales, y en ello, de la creación psicoanalítica. Al igual que la elaboración onírica (Freud, 1900), la imagen cinematográfica opera como registro condensado de los procesos de elaboración, negación e integración de los contenidos surgidos desde el Psicoanálisis en la cultura, propios de los focos de producción de la industria fílmica, dando cuenta de la recepción, masificación o invisibilización del saber psicoanalítico.

\section{El lugar del Psicoanálisis en la cultura contemporánea}

No obstante, antes de adentrarse en el campo de las imágenes fílmicas, cabe preguntarse por la vigencia u obsolescencia del Psicoanálisis al interior de la cultura. Žižek (2008) propone considerar tres niveles de reflexión: Primero, en el campo del conocimiento científico, donde el modelo neurobiológico de la mente humana parece superar al freudiano. Segundo, en el campo de la clínica, donde el tratamiento psicoanalítico pierde terreno frente a los medicamentos (principalmente ante los psicofármacos atípicos y de tercera generación). Por último, en la dimensión del contexto social, donde la idea de una sociedad normativa que opera reprimiendo poderosamente el despliegue de las 
pulsiones sexuales, cede ante una sociedad más permisiva, articulada desde las demandas de un hedonismo narcisista a ultranza (Lipovetsky, 2003).

Desde este prisma, el Psicoanálisis -tradicionalmente señalado como refractario a la empresa reduccionista y racionalista de la experiencia humana (Roudinesco, 2000)-, no puede negar su dependencia y convergencia con el espíritu de la época en que nace. Ciertamente, ocupó un lugar paradojal al interior del discurso de la modernidad, permitiendo el retorno de todo cuanto habitaba el cenit del alma humana premoderna, pero sin librarse del imaginario de su época y del efecto instituido de éste sobre sí, como creación cultural radicalmente atravesada por los valores occidentales de inicios del siglo XX.

Bajo esta mirada, el Psicoanálisis ostenta una singular presencia en el orden de las ideas e imágenes contemporáneas, se deslinda de los relatos modernos centrados en la conciencia y la subjetividad, y al mismo tiempo funda un campo de conocimiento, cuya resonancia se desliza más allá de sus fronteras teóricas, inscribiéndose en la representación del sujeto moderno. Se constituye en un referente comprensivo del escenario que permitió su emergencia, cuyos efectos dan cuenta de su innegable presencia en el orden social.

Así, el lugar del Psicoanálisis y del Psicoanalista se ha construido con tal refinación y artilugio que, tomando los ropajes de las ciencias positivas, han heredado los poderes del oráculo, de la experiencia chamánica y de cierto misticismo de la tradición judeo-cristiana, cubriéndose al mismo tiempo con una supuesta condición de neutralidad. Así, vemos en la creación del dispositivo analítico un esfuerzo explícito por librar esta escena de la fuerzas de las determinaciones sociales, realizando un movimiento estratégico singular, pues a la hora de dar cuenta de su quehacer ante la opinión pública, responde, pero en sus propios términos (Castel, 1980).

No obstante, apelar a la singularidad del fenómeno estudiado, es obviar la complejidad de otros campos cuya especificidad no incide en el enclaustramiento teórico, discursivo o ideológico. En esta mirada, Althusser (en Larrain, 2008) señala que la dimensión ideológica del discurso actúa como desconocimiento, silencio de aquello que por su invisibilidad ejerce influencia sobre el resto, trasfondo cuya presencia inarticulada puebla cada campo de la convivencia humana, cargando de significados incuestionables los espacios de legitimo extrañamiento respecto del orden que es vivido como dado, cuando ante todo es fruto de la creación de los hombres que lo viven y se someten a él.
En esta línea, Castoriadis (1975; 2002), sostiene que un amplio campo de la funcionalidad de las instituciones se articula desde coordenadas ajenas a la pragmática, y muchos de los aspectos de la actividad humana responden a imperativos distantes a su contingencia. Desde estos referentes, es posible esbozar una primera lectura respecto de la particular relación del Psicoanálisis con el poder, o en efecto, a partir de la negación de dicha relación, de hecho Castel nos recuerda que los autores psicoanalíticos han tratado esta tópica, no obstante, en general, abordando el problema de su relación con el poder para eludirlo de forma refinada (Castel, 1980).

Pese a esto, las lecturas críticas y refractarias al discurso hegemónico son cada vez más frecuentes, al igual que la resistencia de "esta historia" a la interpelación de otros relatos, a participar en un dialogo que permita divisar con claridad el lugar de lo psicoanalítico respecto de otros fenómenos humanos, con los que se encuentra en evidente cruce; el mundo académico, las causas políticas, los movimientos y las fuerzas que, desde la marginalidad, cuestionan el estado de las cosas sociales.

De esta manera, "la gran historia del Psicoanálisis", promovida y ostentada por las sociedades y asociaciones psicoanalíticas, se ofrece como imagen de coherencia, oscureciendo toda posible fractura en su identidad, luego del sinuoso recorrido que la ha instalado en la contingencia cultural (Roudinesco, 2000). Pero, el foco en este punto, es la de dar cuenta de la presencia de otra historia, aquella construida por la cultura de masas, distante de los mecanismos de control institucional e inscrita en los referentes de consumo y, por lo tanto, retraducida en el orden social como producto cultural.

Así, el Psicoanálisis, se presentaría como uno de los puntos culmines del saber de su época, heredero de los logros y transformaciones propiciadas por la revolución industrial, pero a su vez, participaría de la progresiva fractura de la representación cristalizada del ser humano, y del orden construido desde los referentes del pensamiento clásico. Así, el Psicoanálisis participaría en la construcción de una nueva imagen del sujeto de la modernidad, entregando al orden cultural nuevos referentes, no sólo conceptuales, sino también poderosamente iconográficos, que prontamente se masificarán gracias a su singular convergencia con el despliegue de los medios de masas, de ellos, el Cine desempeñará un papel protagónico.

Es esta imagen, o las imágenes del Psicoanálisis, sus puntos de convergencia o divergencia, respecto de las tradiciones teóricas de las que se originarían, la que nos 
orientarán sobre las resonancias de una práctica cuya incidencia excede el campo de lo psicológico y, parece susceptible de constantes y heterogéneas apropiaciones culturales; literatura, cine, teatro, música, etc.

\section{El Cine y las Imágenes de lo Psicoanalítico}

Es momento de retomar el camino trazado en torno al Cine, a fin de entender cómo éste puede devenir en sostén y vehículo útil para entender el espíritu de la modernidad y, dentro de ella, del Psicoanálisis. El Cinematógrafo se ofrecería al hombre contemporáneo como ventana privilegiada para dar nuevas formas $\mathrm{y}$ sentidos a aquella dimensión humana, habitada por una realidad siempre esquiva al orden de la racionalidad positivista (Rancière, 2001). En este sentido, como artefacto tecnológico conlleva un estatus paradojal, debe comprenderse como resultado de los avances de su tiempo, poseedor de valor instrumental en cuanto fruto del discurso del pragmatismo moderno, pero a su vez, plataforma que permite el despliegue de determinada sensibilidad que dará forma al caos que subyace a la realidad cotidiana (Castoriadis, 2007), como escenario único que permitiría la entrada del registro de la experiencia humana desdeñada por la razón abstracta de la modernidad.

Desde esta mirada, el Cine como fenómeno cultural converge con la noción de Razón Sensible propuesta por el Michael Maffesoli (1997), en cuanto se ofrece como recurso al espacio social para encarnar lo anómico, contradictorio, ominoso y marginado de la realidad misma, pensarlo por medio de la creación de formas visuales que integren aspectos que se resisten a la racionalidad instrumental, de forma tal que, como producto de la cultura, la empresa del Cine crea objetos por los cuales construye y reconstruye su entorno, otorgando sentido y forma a una externalidad que, privada de la producción del arte, es mera superficie. En este punto, nos encontramos con una lectura opuesta al sentido común, el Cine no sólo representa, por el contrario, da forma a su realidad en cuanto participa de la materialización de lo imaginario, como externalidad ideológica de las fantasías que habitan el cenit de la experiencia humana, como retorno de los contenidos exiliados de la razón instrumental.

Desde esta lectura, es posible considerar al Cine y la producción cinematográfica que ha tomado como objeto directo o contingente al pensamiento psicoanalítico -aquí la razón por la cual se toma esta forma de producción cultural y no otra-, como una construcción audiovisual en torno al Psicoanálisis, los psicoanalistas y las imágenes de ellos ofrecidas en la pantalla, que sería un contrapunto al registro de su desarrollo institucional, apelando a la existencia de una memoria contenida en los márgenes de su decir oficial, cuyo valor está condicionado a aceptar que la historia del pensamiento psicoanalítico excede los límites del dato historiográfico. Por lo que el Psicoanálisis, no es sólo un saber sobre el inconsciente, también puede considerársele el resultado de un proceso complejo de creación colectiva, por el cual el inconsciente y la teoría psicoanalítica en su conjunto, serían la encarnación de una construcción cultural estrechamente ligada, pero en parte autónoma, de lo que los psicoanalistas piensan que es el objeto de su disciplina.

Con estos antecedentes, se propone rastrear el recorrido y registro de la imagen y del imaginario cinematográfico, del saber construido desde la matriz conceptual inaugurada por Freud; el Psicoanálisis. En esta lógica, es posible reconocer en estos discursos elaborados por medio de la imagen cinemática, los fundamentos de un estatuto propio al texto fílmico, como dispositivo dotado de potencialidad evocativa y sintética, que permitiría trazar un recorrido de la presencia y ausencia de la figura del Psicoanálisis a lo largo del Cine. Por lo tanto, en la saga de encuentros y desencuentros de lo Psicoanalítico y la creación Cinematográfica, este último adquiere la potencialidad de hablarnos en el lenguaje de las imágenes, del devenir de la creación freudiana, como sostén de los procesos de elaboración teórica e ideológica, por las cuales el Psicoanálisis en sus distintas formas puede pensarse a sí mismo y ser pensados.

\section{EI Valor de la Imagen Cinematográfica y sus posibilidades Metodológicas}

Las películas evocan, tanto en el amateur como en el especialista, no sólo su apreciación estética, también desencadenan esfuerzos comprensivos y analíticos de distintas complejidades y magnitudes. De manera tal que, la mirada o las miradas proyectadas sobre un film, prontamente adquieren una connotación analítica, desde el momento en que el espectador/investigador disocia un aspecto de la totalidad, para interesarse en un momento determinado, en una imagen o parte de ella (Aumont \& Marie, 1990), giro en el cual la atención se dirige al detalle, por lo cual es posible sostener que el análisis es una actitud común al crítico y a todo espectador un tanto consciente. 
Ahora, con relación al uso del Cine como soporte material de una investigación, esto implica trabajar con un tipo de documento cuyo estudio se encuentra en proceso de constante creación teórica. $\mathrm{Al}$ respecto, Aumont y Marie (1990), han propuesto considerar las películas como obras artísticas autónomas, susceptible de engendrar un texto, que fundamenta sus significaciones sobre estructuras narrativas y sobre bases visuales y sonoras, produciendo así un efecto particular sobre el espectador, dando origen a un artefacto cultural inscrito en la historia de las formas, de los estilos y de la evolución de estos.

En las diversas vías ensayadas para el acceso a aquello que descansaría en los films, se han usado diferentes modos de aproximación, dirigiendo el foco de atención a los distintos componentes de los cuales se nutre lo fílmico. De hecho, y siguiendo la lectura de Rogerd Odin (1983), el film no propondría ningún análisis en si, simplemente bloquea posibles vías de aproximación. Por lo tanto, no existe un método de análisis general cinematográfico, cada uno se debe ajustar y calibrar a las características del film y de aquello que se espera abordar en él.

Una de las propuestas metodológicas, la desarrollada por Rosenstone (2008), hace uso del Cine como una materialidad, donde el texto fílmico se concibe en cuanto una forma visual de pensamiento histórico, cuya potencia no descansa en la mayor o menor fidelidad a una pretendida "realidad histórica", pues las películas no son espejos de la realidad sino construcciones que hacemos de ellas y forman parte de esta. En esta mirada, la condición privilegiada del texto cinematográfico es ser un discurso que nos permite pensar y entender el pasado, en una plasticidad en constante transformación, pues ningún discurso es absoluto ni definitivo sino que se inscribe al interior de otros relatos que constituyen un discurso mayor.

En consecuencia, las películas nos hablan de las sociedades que las han realizado, difundiendo y expresando el ideario de su época, pues el Cine se ha formulado desde el presente de su fabricación, emitido desde la mentalidad de su época, bajo sus coordenadas, sus intenciones, estética y su razón de ser (De Pablo, 2008) Y en este dialogo, la producción cinematográfica no es un receptor pasivo de los contenidos histórico sociales, se ha constituido en un actor inscrito en los relatos de la cultura como interfaz de sus producciones, masificando y reelaborando en nuevas formas parceladas de la realidad que, previas a su aparición en la pantalla, estaban desprovistas de imágenes que les permitiesen ser pensadas.
De esta forma, la imagen del film, inscrita en el cine o el televisor, releva la función que en algún momento fue exclusiva de las formas escritas, tendiendo a sustituirlas, masificándose gracias al poder de los medios de comunicación (Ferro, 2008) Así, son las imágenes, más que lo escrito, las que configuran la memoria y comprensión de esta para las nuevas generaciones (Ferro, 2008), influyendo en la vida de las sociedades como informador privilegiado del pasado y del presente, reproduciendo las corrientes dominantes de pensamiento $\mathrm{o}$, por el contrario, aquellas que las cuestionan.

En este sentido Rancière sostiene en La fábula cinematográfica (2001), una relectura de la función del Cine y propone un nuevo estatus para la estética y la ficción cinematográfica, lo que denomina políticas estéticas, donde el Cine es concebido como un registro capaz de conmover, a través de los movimientos sensibles de la cámara y la capacidad polisémica de las imágenes, los estados del ánimo y la conciencia social de los espectadores. Así, la ficción se impone a los hechos, como un más allá de la misma realidad de la cual se nutre, transformando los matices de los registros históricos, redescribiéndolos. De esta forma, el Cine posee la capacidad de operar como una zona cero de la historia, donde es posible pensar el pasado más allá de las verdades literales, como verdades simbólicas opuestas a las narrativas históricas tradicionales, se constituyen en "respuestas narrativas" a las conflictivas de la sociedad contemporánea, encausadas al logro de un sentido del pasado.

Este último aspecto da cuenta de la presencia inevitable en la producción cinematográfica de la dimensión ideológica, que antecede a todo discurso manifiesto en torno a lo visible o no visible en el Cine, constituyéndose en testimonio de los procesos represivos e inclusivos del orden social. Pues, como lo indica acertadamente Sorlin; "el cine no es sólo el reflejo de su época, pertenece a ella creando figuras, fenómenos, modos de ser, ejerce acción en ella" (2008, p. 26). Por esta misma razón, toda producción cinematográfica debe reconocerse como una concreción presente, un objeto contingente de la cultura. Y en su materialidad, influye en la percepción que el individuo tiene de sí mismo y del mundo que le rodea; genera hábitos, normas de comportamientos, mentalidades, formas de vida y mitos, conformando el imaginario de generaciones enteras.

El Cine nos permite acceder a costumbres, gestos y formas de pensar, dando cuerpo y rostro a realidades que, de no ser así, permanecerían marginales o desprovistas de imágenes sociales que las conviertan en cercanas y accesibles a la mirada del sujeto común. 
Una segunda opción metodológica, consiste en reconocer en el texto cinematográfico la existencia de un testimonio sobre el espíritu o la atmosfera de determinada época (Sorlin, 2008), marca que traspasa los límites definidos por los contenidos narrativos o visuales de la creación en sí, dando cuenta de las condiciones de producción, de los compromisos o tensiones manifiestas o subyacentes, de determinada situación social, política e ideológica entre otras, singularizada en la imagen cinematográfica. A esto, se puede añadir una tercera opción complementaria, desarrollada inicialmente por Marc Ferro (en Sorlin, 2008), la de dirigir la mirada hacia los errores, vacilaciones y no coincidencias en las películas, señalando en esos los lapsos, aquellos que el investigador utilizará como agentes reveladores de lo que yace bajo lo aparente, lo invisible que permanece cubierto por el semblante de lo visible.

Llegados a este punto, se esboza un posible estatuto del Cine como Objeto de las Ciencias Sociales, en consecuencia la pregunta ya no es, si es factible el uso o no de determinada película, sino qué es lo que se ha de observar en ellas.

Ante el problema concreto del análisis de un film, no está de más señalar que esto no consiste simplemente en ver una película, pues la relación a establecer con el objeto de estudio requiere una aproximación profunda, que revise en lo posible, hasta sus últimos aspectos. No obstante, en opinión de Gómez Tarín (2006) y Montiel (1992), este es un proceso interminable, desprovisto de un punto de definición pleno y estable, que demanda del investigador su renuncia a toda expectativa de una apropiación definitiva y completa del objeto examinado. Punto de convergencia con la obra de Ricoeur, quien al abordar el problema de la interpretación de un texto, sea cual sea su forma expresiva, señalará: "El símbolo da que pensar, hace una llamada a la interpretación, precisamente porque dice más de lo que no dice y de lo que jamás termina de no decir" (Ricoeur, 1969 en Agis, 2006), por lo tanto, estamos ante una tarea siempre abierta, donde todo texto cinematográfico, en cuanto texto, es susceptible de reinscribirse con cada nueva lectura.

Establecidas estas consideraciones, resulta pertinente regresar al tema de los objetivos del análisis de un film. En opinión de Aumont y Marie (1990), el fin del análisis es elaborar una "especie" de modelo del film, proceso de construcción que demanda una previa distinción, consistente en diferenciar entre el film como película y el film como proyección, siendo esto último aquello que se encuentra entre lo móvil y lo fijo de la obra cinematográfica.
En consistencia a lo anterior, se desprenden dos grandes procesos propios de todo análisis cinematográfico: la descripción y la interpretación (como mecanismos productores de sentido), y sobre ellos se puede edificar un esquema metodológico acorde con lo singular de cada Film y los objetivos de investigación perseguidos. De manera tal, que la descripción será el primer paso hacia la interpretación, pues para establecer cualquier tipo de hipótesis sobre el film, es necesario anclarla en un punto de partida que responda a precisiones de orden material directamente extraídos del significante fílmico (Aumont, 1996).

Y el soporte material del objeto fílmico, es obviamente la imagen, unidad en apariencia accesible y de fácil abordaje, pero que como fenómeno aprehensible para el estudio de sus contenidos manifiestos e implícitos, muestra una complejidad que va más allá de la mera descripción pues, como propone Aumont (1996), describir una imagen implica prestar atención a lo que ésta contiene, y a las partes como un todo, y a su vez, a las partes de las partes, pero también a todo aquello que se disemina y resiste a formar parte de la totalidad, por tal razón, cada análisis fílmico puede concebirse como una tarea de dos pasos; el primero es descomponer, deconstruir el film en sus elementos constituyentes, y el segundo establecer relaciones entre tales elementos para comprender y explicar los mecanismos que les permiten constituir un todo significante.

Desde esta lógica, la descripción de una imagen debe permitir la emergencia de elementos que contengan más información, capaz de vincularse con otros elementos presentados anteriormente. Estos elementos, unidades de análisis que son las imagen, no emergen espontáneamente ante el observador, ya que el análisis de un film tiene que ver con establecer unidades relacionales abstractas, que no ocupan una superficie fílmica manifiesta, en consecuencia, metodológicamente no existe una inmediatez del texto fílmico.

Como insisten Aumont, Bergala, Marie y Vernet, en Estética del Cine (1983), toda figuración, representación conduce a la narración, aunque sea en potencia, por el peso del sistema social al que pertenece lo representado en la imagen, y por su ostentación. Así, el cine ofrece a la ficción, por medio de la imagen en movimiento, una duración y una transformación, que propician el encuentro entre el Cine y la Narración.

$\mathrm{Si}$ se ha de concebir un film como texto cinematográfico, es pertinente precisar de qué hablamos cuando ocupamos la noción de texto, las respuestas son diversas, pues mucha tinta se ha gastado tratando de delimitar lo que sería propiamente un texto. Acá 
el recorrido se restringirá a planteamientos que han incidido de forma directa o indirecta en el campo del análisis de los textos cinematográficos.

Podemos tomar como punto de partida la definición propuesta por Ricoeur (en Agís, 2006) donde un texto puede definirse como una estructura igual o superior a una frase, sin ser tampoco una suma de todas ellas. Es un proceso acumulativo, holístico, con una estructura especifica (Ricoeur en Agís, 2006) Entonces, un texto es un tejido, una textura de múltiples engarces y procedencias, donde el autor será solamente una huella, una marca de un conglomerado multisignificante (Kristevas en Gómez, 2005). Se ha tomado esta definición por dos motivos; el primero, porque la autora ofrece una bella imagen que permite pensar las complejidades del texto. El segundo, por remitir la noción misma a la problemática de la autoria, pues cabe preguntar, frente a todo texto, quien es su autor, a quien nos remite la experiencia de mirar/ ver una obra cinematográfica.

Aumont, Bergala, Marie y Vernet (1983), señalan que al hablar de texto fílmico, se considera al filme como un discurso significante, del cual es posible analizar su o sus sistemas internos y estudiar todas las configuraciones significantes que se puedan observar.

Desde este prisma, es atingente considerar la distinción desarrollada por Raymond Bellour en El Texto Inencontrable (s/f), entre Obra y Texto. Para él, la obra se comprende como un fragmento de sustancia, un objeto asible, presente en un sentido fenoménico, como objeto acabado computable, que puede ocupar un espacio físico. Por el contrario, el texto se sostiene con el lenguaje, es un campo metodológico, como producción, como travesía.

Por último, Barthes (1990) lleva a un nivel de mayor radicalidad la diferenciación entre obra y texto, negándose a considerar las obras como simples mensajes, o enunciados que den cuenta de objetos acabados, por el contrario, insistirá en el estatuto de las obras como producciones perpetuas, enunciados por los cuales el sujeto continúa pensándose, tanto el autor, como el lector. Estableciendo la equivalencia entre la escritura y la lectura, en una lógica donde el sujeto del análisis no es exterior al lenguaje, pues no hay discurso sobre la obra, sino la producción de otro texto de igual valor que dará origen a la intertextualidad.

De esta forma, para Aumont y Marie (1990), el análisis textual habitualmente, y no sin malos entendidos, se ha asumido como una especie de equivalente general del análisis sin más, pero no es así, de hecho, es posible reconocer, en términos generales, un itinerario que se ha trazado del análisis textual en el campo de los estudios del objeto cinematográfico.

En este campo, la Imagen adquiere valor central como unidad elemental de análisis, en cuanto registro palpable capaz de otorgar al mundo una perspectiva de si mismo. En consecuencia, la Imagen Cinematográfica ocupa un lugar de encuentro y articulación entre la realidad y su representación, como forma de pensamiento privilegiada sobre el sujeto, los valores de su época y las conflictivas que tensionan determinado momento histórico (Goddard en Gómez \& Vilageliu, 2005).

De esta manera, la imagen que nos ofrece el Cine como producto social, es un objeto cuya naturaleza se rehúsa a toda suerte de división, reducción o sometimiento a metodologías de análisis que la desliguen del contexto en el cual adquiere y genera sentido, ya que forma parte de la realidad que busca representar, pues está inserta en cadenas de significación aún más amplias que la misma película.

Cada fotograma del texto cinematográfico, como imagen, se ha de vincular en forma directa o indirectamente a determinadas representaciones, en las que podemos reconocer equivalencias con otros sistemas de imágenes utilizados por la sociedad. Por lo tanto, cualquier interpretación debe tener en cuenta esta particular forma de intertextualidad (Barthes, 1990). En consecuencia, para Sorlin (1996), toda película puede considerarse parte de una totalidad mayor, conformada por el conjunto de todas las obras cinematográficas filmadas, entonces, cuando se hace uso de las imágenes del Cine como producción social, lo que se debe considerar como horizonte conceptual es el contexto general: el universo del Cine.

\section{La Imagen Cinematográfica y el Fantasma del Psicoanálisis}

Antes de dar paso a la propuesta de abordaje de lo Psicoanalítico en el Cine, tal como se ha desarrollada hasta ahora, es necesario dar cuenta de los esfuerzos que la anteceden, y de las restricciones que los intentos de comprensión y sistematización del lugar del Psicoanálisis al interior de la producción cinematográfica, han encontrado.

En el universo cinematográfico, el Psicoanálisis y los Psicoanalistas han tenido una presencia más bien fantasmática, a momentos manifestándose a plena luz del día como protagonistas o agentes determinantes en el desarrollo dramático de los filmes. El resto del tiempo, la presencia de lo psicoanalítico se torna difusa, 
incierta, enigmática y maleable a los más diversos caprichos teórico-conceptuales, con tal de ajustarla a las necesidades narrativas del texto fílmico.

En este itinerario, el primer registro documentado se remonta a 1906 con el filme mudo "El Sanatorio del Dr. Dippy" (Gabbard \& Gabbard, 1999), primer registro ante esta nueva forma de representación, de un ejercicio igualmente novedoso: el Psicoanálisis. Así, las primeras recreaciones de la psicoterapia fueron las realizadas por D. W. Griffith en The Criminal Hypnotist (1909).

Desde este momento fundacional, es posible trazar un cierto recorrido del Psicoanálisis y de sus practicantes, empresa en la que se han embarcado, con distintos enfoques, un grupo de investigadores de los que cabe destacar el trabajo de Glen Gabbard y Krin Gabbard, quienes en Psychiatry and the Cinema (1999) pesquisan la imagen y la iconografía de los profesionales de la salud mental a lo largo de la historia del Cine, describiendo el cambiante trato que ha tenido el Cine con el Psicoanálisis y los profesionales a fines (cabe señalar que la misma ambigüedad con que es abordada la figura del Psicoanalista da cuenta de lo esquivo y evanescente que resulta el Psicoanálisis al interior del Cine, constantemente mimetizado con otras disciplinas y, al mismo tiempo, impregnando de un halito misteriosos espacios ajenos e inesperados para la práctica analítica).

Entre 1906 y 1957, los psiquiatras y psicoanalistas -figuras pobremente diferenciadas- se retratan como bufones de experiencia cuestionable o, por el contrario con características positivas superiores, capaces de tornar posible lo imposible. Entre los años 1957-1963, los psicoanalistas y demás profesionales de la salud mental, gozan de una mejor fama, son representados como eficaces, compasivos o talentosos, solucionando crímenes, siendo el mejor ejemplo de esto, Simon Oakland el psiquiatra encargado de periciar a Norman Bates en Psycho (1960) dotado de una notable sabiduría y omnisciencia al momento de desentrañar la naturaleza patológica de Norman.

A partir de 1963, y en gran medida como fruto de la vinculación de los profesionales de la salud mental, a la empresa bélica iniciada con el conflicto de Vietnam, el Psicoanálisis participa de la caída en desgracia que caracterizó a un Cine afín a las criticas emanadas desde la Antipsiquiatría, actuando a momentos como amplificador y promotor de sus planteamientos. En este escenario, el analista deviene en un bufón, sádico, o un personaje de otro modo malévolo.

Durante este período, la película antipsiquiátrica emerge llevando el tema del héroe -la mayoría de las veces un paciente- como una figura que desafía la institución psiquiátrica, develando sus defectos y los de la sociedad de la cual es reflejo, en un derrotero que se recorre a expensas de su propia destrucción. Películas inscritas en esta línea son: King of Hearts (1966), One Flew over the Cuckoo's Nest (1975), Hombre Mirando al Sudeste (1986), y House of Games (1987).

Desde un vértice cercano, Irving Schneider (1985) trazó un análisis abocado a sistematizar tipologías y estereotipos predominantes en la representación del profesional de la salud mental. A partir de este esfuerzo, Schneider propone en 1985 una tipología para clasificar los estereotipos de los psicólogos y psicoanalistas que se presentan en las películas, sosteniendo que tres de las cuartas partes de los profesionales retratados son clasificables en uno de tres estereotipos cinematográficos: Dr. Dippy, Dr. Wonderful, y Dr. Evil.

El Dr. Dippy es el psiquiatra estrafalario, que está más loco que su o sus pacientes, por su parte, el Dr. Wonderful es un ser humano, modesto, y creativo, y finalmente el Dr. Evil es peligroso y subversivo. Luego, desde esta primera clasificación, Harriet Schultz añade dos nuevas tipologías; el Dr. Rigid, que ahoga la felicidad y la creatividad y la Dra. Line-Crosser, que es incapaz de mantener las fronteras seguras entre paciente y terapeuta.

A esta primera tipología se sumará una desarrollada por Glen Gabbard y Krin Gabbard (nuevamente), quienes han subdividido los estereotipos en 10 categorías básicas (Gabbard \& Gabbard, en Fink \& Tasman, 1992): El libidinoso (Novedades, Pussycat?), el Búfon Excéntrico (Bringing Up Baby), El Apático, Frío y Egoísta (The Deer Hunter), El Racionalista (Poltergeist III), La represiva Agente de la Sociedad (Harold y Maude), La Mujer Incompleta (Knock on Wood), El Doctor Mente Siniestra (When the Clouds Roll By), El Psiquiatra Vengativo (Dressed to Kill), El Detective Omnisciente (Psycho), y El Curador Dramático (The Snake Pit).

Por su parte, y con una metodología distinta, Coleman (1995) utiliza un enfoque cuantitativo y examina la representación de 53 psicoterapeutas en 45 largometrajes, entre los años 1945 y 1994. En ello encontró, que los psicoterapeutas fueron retratados negativamente en una de cuatro maneras: (1) las personas independientes que tienen fallas y aún se transforman a través de sus interacciones con los clientes, (2) Los investigadores cuyos proyectos dañan a otros, (3) Las personas que se entregan a sus "sombras" y cosechan las consecuencias, y finalmente, (4) caracteres mínimamente visibles que quedan sin cambios durante toda la película. 
Por último, una década más tarde, Wedding \& Niemiec (2003) ofrecieron un sistema de clasificación temática, haciendo hincapié en la tendencia de las películas para presentar a los psicoterapeutas (y dentro de éstos a los Psicoanalistas) como personajes que podrían encajar en una de las siguientes secuencias: Resuelto y Autoritario (K-Pax, Three Faces of Eve); Arrogante e ineficaz (I Am Sam, What About Bob?); Seductora y poco ética (Bliss, Final Analysis); Insensible y autoritario (Spider, One Flew Over the Cuckoo's Nest); Pasiva y apática (Anything Else, Patch Adams); Astuto y manipulador (Vanilla Sky, Basic Instinct); Peligroso y Omnisciente (Gothika, Silence of the Lambs); y Motivador y bien intencionado (Antwone Fisher, Good Will Hunting).

Es evidente que sobre el Psicoanálisis y los Psicoanalistas en el Cine, se ha escrito bastante, más de lo que podría esperarse para una disciplina tan especifica y plagada de complejidades conceptuales. Ante esto, cabe realizar a lo menos dos preguntas: ¿Cuál es el motivo de esta aparente fascinación del Cine por el Psicoanálisis? Y ¿Cuál es la razón o razones que mueven a los realizadores a retratar al Psicoanálisis y sus practicantes teñidos con tan diversos, y momentos contradictorios, ropajes? Respecto a la primera pregunta, el psiquiatra y académico cinematográfico Irving Schneider, dijo una vez: "Si la psiquiatría -y esto lo considero aplicable al Psicoanálisis- no hubiera existido, las películas habrían tenido que inventarla". Es más, hace ya un tiempo, el crítico de cine Parker Tyler se refirió al cine casero como la" clínica psicoanalítica del trabajador medio".

Ahora bien, y volviendo a la pregunta señalada, una posibles explicación está en reconocer que el psicoterapeuta (sea este analista o no) ha sido siempre un recurso argumental maravilloso para los cineastas. Aunque un narrador omnisciente puede describir la vida interior de la protagonista de una novela, el medio cinematográfico debe recurrir a una voz en off o una elaborada exposición que lleva lejos de la acción. Por el contrario, una salida más simple es que el protagonista visite a un terapeuta, para que el público pueda ver una parte del carácter que no se revela en la acción de la narración.

En cuanto a la segunda pregunta, difícilmente se pueda ensayar una respuesta definitiva. No obstante, la psicoanalista Helen Taylor Robinson (en Sabbadini, 2003), desde una perspectiva claramente freudiana, desliza una posible explicación dirigiendo su mirada al creador artístico.
En su tesis, sostiene que el Psicoanálisis es una amenaza universal al narcisismo humano, ya que el proceso analítico está diseñado para señalar todo nuestro primitivismo, debilidad, falibilidad, limitaciones, y fealdad. De esta forma, y en respuesta a estas amenazas narcisistas, sería natural que la consciencia se resista y ataque la fuente de la amenaza. Así, Taylor Robinson considera a los analistas como nobles y bien intencionados, mientras que la rabia de artistas, creativos y pacientes está exclusivamente al servicio del mantenimiento de una ceguera ante "las verdades psicoanalíticas".

Desde este punto de vista, la crítica negativa o sátira mordaz al Psicoanálisis es transferencia pura y, además, sirve como prueba de que el proceso es profundamente amenazante. En el pensamiento de Taylor Robinson, ya que el análisis invariablemente -y con precisiónapunta a la defensa del deseo, ciego ante sus propias limitaciones y su horror, el poder del Psicoanálisis debe ser neutralizado, y los ataques serían prueba positiva de que cada analista burlado o concepto analítico, ha llegado demasiado cerca de la incomodidad. Así, cuando el análisis es atacado o retratado como tonto por los creadores, se demuestra solamente lo contrario: es decir, la amenaza en el centro del proceso analítico está en contacto con un nervio inherentemente vulnerable para el narcisismo.

De esta manera, para Taylor Robinson, "el ataque cinematográfico" se trata de un crédito, tanto para el Psicoanálisis y la validez de su potencia. Desde esta perspectiva, no puede haber ninguna razón justificada externamente para burlarse o criticar la disciplina, ya que el analista prototípico es visto participando exclusivamente como un intérprete de buenas intenciones, objetivo de los otros inconsciente, sin que la propia subjetividad del analista o su inconsciente se entrometa en todo.

Por último, y en esta misma lógica, el novelista y cuentista Daniel Menaker (1999), cuyas obras están llenas de referencias al Psicoanálisis, y en una es el tema principal, ha sostenido que mucho de la situación analítica y sus efectos, al ser retratados por los medios como tontos, indulgentes, falsos, y conspicuos están al servicio de los esfuerzos de negar la unidad de los estados mentales aterradores que los analistas amenazan con exponer a las personas, de forma tal que, al igual que los pacientes analíticos, los artistas creativos se "resisten a la conciencia de los estado mentales aterradores originados de la ira, una ira expresada por lo que los analistas son vistos como tontos, desacreditando todo el proceso psicoanalítico". 


\section{Conclusión/Propuesta... El Cine como fantasma del Psicoanálisis}

Llegados a este punto, no cabe duda que el Psicoanálisis suscita interés en la industria cinematográfica, y por defecto en los estudiosos del Cine, develando en reiteradas ocasiones, cómo este arte se ha nutrido de la teoría psicoanalítica.

Son muchos, y renombrados, los cineastas que reconocen en la empresa iniciada por Freud una fuente de inspiración y aprendizaje, aceptando la relación tributaria que tendría el Cine respecto del Psicoanálisis. De igual manera, ya es habitual ver como los psicoanalistas echan mano de los textos cinematográficos para graficar complejos procesos que, desprovistos de la imagen cinemática, quedarían entregados a elaboraciones teóricas excesivamente abstractas.

Pero la pregunta a desarrollar aquí, como propuesta de investigación, y que justifica la detención en los fundamentos del análisis cinematográfico es: ¿Qué es aquello que el Cine nos puede enseñar sobre el Psicoanálisis? ¿De qué nos habla el Cine cuando dirige su mirada al Psicoanálisis? ¿Qué es lo que el Cine -en su pensamiento en imágenes-, sabría del Psicoanálisis y los psicoanalistas desconocen, o se niegan a reconocer?

Desde esta perspectiva, se propone indagar, desde el campo de los textos audiovisuales, en aquel discurso difuso, fantasmático, que subyacería a las imagenes manifiestas con que la industria cinematográfica ha retratado al Psicoanálisis.

En consecuencia, se sostiene que, más allá de las formas que han derivado en tipologías y estereotipos, subyace una cierta teoría en los medios de masa de lo qué sería el Psicoanálisis, deslizando una historia y un itinerario de la disciplina, que va más allá del discurso oficial, contextualizado por los derroteros de las culturas que lo han recepcionado. De esta forma, en el análisis de la reconstrucción cinematográfica del Psicoanálisis, descansaría otra imagen, aquella que ha surgido de la recepción y apropiación cultural de sus discursos, como retorno de un registro que ya no le pertenece, y espera por ser visto.

A partir de esta apuesta, es decir, la afirmación de que la Producción Cinematográfica deslizaría desde y hacia la cultura cierta verdad sobre el Psicoanálisis que éste ignora o niega, es que se reconoce en las Imágenes de la Práctica Psicoanalítica, no sólo un conjunto de representaciones y estereotipos diversos sobre el practicante de la disciplina y su entorno, también emerge la posibilidad de develar en estas producciones iconográficas el registro de cierto relato estético sobre el Psicoanálisis, es decir, un pensamiento en imágenes no articulado pero latente sobre la teoría, la práctica y, a lo menos, sobre la institución psicoanalítica.

En este sentido, las imágenes que el Cine ofrece sobre "lo psicoanalítico" son algo más que representaciones sociales, pues en su naturaleza visual, se despliega el campo de lo imaginario que, como magma de las significaciones sociales (Castoriadis, 1975), se ofrecen como registros autónomos, no institucionales y, en apariencia, librados de los compromisos y las cargas teóricas e ideológicas que el Psicoanálisis habría ceñido sobre su propia imagen.

Cabe indicar en este punto, que no se pretende sostener que el Cine sea ajeno a las coordenadas ideológicas o teóricas propias de sus focos de producción, por el contrario, es precisamente desde ellas donde se espera pesquisar las construcciones iconográficas que moldean su relato audiovisual, pues serían las imágenes Cinemáticas del Psicoanálisis la ventana de acceso a la inscripción fantasmática de la creación freudiana en la cultura.

Así, el Cine, y más precisamente, el uso y apropiación que éste ha hecho del Psicoanálisis, se presenta como proyección e incluso como retorno sintomático al interior de la cultura, de aquello sobre lo cual la disciplina analítica ya no es capaz de ejercer jurisprudencia, pues el Psicoanálisis de Hitchcock, Bergman, Cronenberg o Lars Von Trier -por nombrar algunos realizadores marcado por el pensamiento Freudiano-, es una creación que se nutre del Psicoanálisis pero lo excede, en cuanto objetos de la cultura que interpelan a su matriz simbólica de origen, ofreciendo imágenes/ significantes que por medio de un relato estético lo releen a la luz de la mirada cinematográfica, como un inconsciente estético del mismo Psicoanálisis.

\section{Referencias}

Agís, M. (2006). Paul Ricoeur: Los caminos de la Hermenéutica. Agora-papeles en filosofía. Universidad de Santiago de Compostela. Aumont, J., Bergala, A., Marie, M. \& Vernet, M. (1983). La estética del cine. Espacio fílmico, montaje, narración, lenguaje. Barcelona: Esitorial Paidós.

Aumont, J. \& Marie, M. (1990). Análisis del Film. Barcelona: Editorial Paidós.

Aumont, J. (1996). A quoi pensent les films. Paris: Editorial Séguier.

Barthes, R. (1990). La aventura semiológica. Barcelona: Editorial Paidós.

Bellour, R. (1995). Le texte introuvable. En R. Bellour, L'analyse du film (pp. 35-41). París: Calmann-Lévy.

Castel, R. (1980). El Psicoanalismo, el orden Psicoanalítico y el Poder. México D. F.: Siglo XXI Editores. 
Castoriadis, C. (1975). La institución Imaginaria de la Sociedad. Tusquest Editores.

Castoriadis, C. (2002). Sujeto y verdad en el mundo histórico-social. Buenos Aires: Éditions du Seuil.

Castoriadis, C. (2007). Ventana al caos. Buenos Aires: Fondo de Cultura Económica.

Coleman, D. (1995). Images of psychotherapists from feature films: 1945-1994. Dissertations Abstracts International. Canada: Editorial University Microfilms.

De Broca (Productor/Director) (1966). King of hearts. [Película] Francia: Productora Les Productions Artistes Associés.

De Pablo, S. (2008). El linaje de aitor en la pantalla. Cine, historia e identidad nacional en el País Vasco. Una ventana indiscreta, 105-130. Recuperado de http://e-archivo.uc3m.es/bitstream/ handle/10016/17752/linaje_pablo_CIHC_2008.pdf?sequence=1

Douglas, M. \& Zaents, S. (Productor) Forman, M. (Director). (1975) One Flew Over the Cuckoo's Nest. [Película]. Estados Unidos: Productora Fantasy Films.

Ferro, M. (2008). El Cine, una visión de la historia. Madrid: Edicioness Akal.

Freud, S. (1895). Estudios Sobre Histeria. Obras Completas, Vol. II. Buenos Aires: Amorrortu Editores.

Freud, S. (1900). La Interpretación de los Sueños. Obras Completas, Vol. IV. Buenos Aires: Amorrurtu Editores.

Gabbard, G. \& Gabbard, K. (1992). Cinematic stereotypes contributing to the stigmatization of psychiatrists. En P. Fink \& A. Tasman (Eds.), Stigma and mental illness (pp. 113-126). Washington, D. C.: American Psychiatric Press.

Gabbard, G. \& Gabbard, K. (1999). Psychiatry and the Cinema. Washington D. C.: American Psychiatric Publishing.

Griffith, D. (Productor/Director) (1909). The criminal hipnotist [Película] Estados Unidos: Productora Silent Era.

Gómez, F. \& Vilageliu, J. (2005). La intertextualidad en Jean-Luc Godard. Cuadernos del Ateneo de La Laguna, (20), 151-160. Recuperado de http://www.ateneodelalaguna.es/pdf/ATENEO20/ pdf/intertextualidad.pdf

Gómez Tarín, F. (2006). Discursos de la ausencia. Elipsis y fuera de campo en el texto fílmico, Valencia: Ediciones de la Filmoteca/ Institut Valencia de Cinematografía Ricardo Muñoz Suay.
Hausman, M. (Productor). Mament, D. (Director). House of Games. [Película]. Inglaterra: Productora Orion Pictures.

Hitchcock, A. (Director/Productor). Psycho. [Película]. Estados Unidos: Shamley Productions.

Larraín, J. (2008). El concepto de Ideología. El marxismo posterior a Marx: Gramsci y Althusser. Santiago, Chile: Ediciones Lom.

Lujan, P. \& Lauria, H. (Productor). Subiela, E. (Director). (1986). Hombre mirando al Sudeste. [Película]. Argentina: Productora Cinequanon Pictures.

Lipovetsky, G. (2003). La era del vacío: Ensayos sobre el individualismo contemporáneo. Barcelona: Editorial Anagrama.

Maffesoli, M. (1997). Elogio de la razón sensible. Barcelona: Editorial Paidós.

Montiel, A. (1992). Teorías del cine. Un balance histórico. Barcelona: Editorial Montesinos.

Menaker, D. (1999) La terapia. Buenos Aires: Emecé Editores.

Odin, R. (1983). Del espectador ficcionalizante al nuevo espectador: enfoque semiopragmático. Objeto Visual, 5, 135-156.

Ranciere, J. (2001). La fábula cinematográfica. Barcelona: Editorial Paidós.

Ricoeur, P. (1969). Le conflit des interprétations. París: Éditions du Seuil.

Rosenstone, R. (2008). Inventando la verdad histórica en la gran pantalla. California: Institute of Technology.

Roudinesco, E. (2000). ¿Por qué el Psicoanálisis? Barcelona: Editorial Paidós.

Sabbadini, A. (2003). The couch and the silver screen. Psychoanalytic reflections on the European Cinema. East Sussex: Editorial Brunner-Routleger.

Schneider, I. (1985). The psychiatrist in the movies: The first 50 years. In J. Reppen \& M Charney (Eds.), The Psychoanalytic Study of Literature (pp. 53-67). Hillsdale: The Analytic Press.

Sorlin, P. (1996). Cines europeos, sociedades europeas: 1939-1990. Barcelona: Editorial Paidós.

Sorlin, P. (2008). Cine e historia. Una relación que hay que repensar. Paris: Universidad de la Sorbona.

Wedding, D. \& Niemiec, R. (2003). The clinical use of films in psychotherapy. Journal of Clinical Psychology, 59(2), 207-215. doi:10.1002/jclp.10142

Žižek, S. (2008). Cómo leer a Lacan. Buenos Aires: Editorial Paidós. 
